\title{
Combined Use of Cerclage, Obstetric Pessary, and Micronised Progesterone in Recurrent Miscarriage
}

\author{
Dobrokhotova Yuliya*, PA Kouznetsov and LS Djokhadze \\ Department of Obstetrics and Gynecology of Medical Faculty, The Russian National Research Medical University, Russia
}

*Corresponding author: Dobrokhotova Yuliya, Department of Obstetrics and Gynecology of Medical Faculty, The Russian National Research Medical University, Moscow, Russia.
Received Date: December 07, 2018

Published Date: December 14, 2018

\begin{abstract}
In recent years, the use of progesterone, cerclage, and obstetric pessaries in patients with cervical incompetence has been studied extensively. However, there have not been any published reports of combined use of these methods. Here, we describe a case of successful combined use of cerclage, obstetric pessary, and micronised progesterone for preterm birth prevention in a nulliparous woman with recurrent miscarriage.
\end{abstract}

Keywords: Cervical incompetence, Preterm birth, Cerclage, Obstetric pessary

\section{Introduction}

Over the past years, the rate or preterm birth in Russia has increased from $4.3 \%$ in 2012 to $4.2 \%$ in 2014 and 4.1 in 2016 [1]. Preterm birth and prematurity are the leading global cause of neonatal death and second leading cause of death in under-fives, after pneumonia [2]. Approximately $5 \%$ of preterm births occur before 28 weeks of pregnancy, 15\% between 28-31 weeks, $20 \%$ at $32-33$ weeks, and $60-70 \%$ at $34-37$ weeks [3]. Preterm birth is associated with nearly $75 \%$ of perinatal mortality cases $[4,5]$, and surviving infants are often at a higher risk of disability, including learning difficulties and vision and hearing impairment [2].

Cervical incompetence and history of preterm delivery are the primary risk factors of preterm birth [5]. Cervical incompetence is a condition associated with functional or structural cervical alterations that prevent a pregnancy from being carried to term and has been reported to account for up to $40 \%$ of very preterm births [6]. After a pregnancy loss in the second trimester, the risk of subsequent pregnancy loss has been reported to increase 10 -fold [7].

There are two main strategies of cervical incompetence management: medical and mechanical. Mechanical strategies include transvaginal and transabdominal cerclage, and obstetric pessaries. The medical strategy is based on the use of progesterone agents.

There is evidence that the use of vaginal progesterone in women with singleton pregnancies and cervical incompetence reduces the risk of preterm births and neonatal morbidity and mortality [8]. A Cochrane meta-analysis published in 2017 reported that preterm births and neonatal mortality were less likely in women who had undergone cerclage [9]. A range of randomized and non-randomized studies demonstrated the efficacy of cervical pessaries in preventing preterm births [10]. However, there is no conclusive evidence on the efficacy of any of these methods in multiple pregnancies. There is also a lack of unified approach and recommendations on how to combine medical and surgical management of cervical incompetence for preterm birth prevention in high-risk women.

\section{Case Report}

Here, we describe a case of successful combined use of cerclage, obstetric pessary, and micronised progesterone for preterm birth prevention.

Ms B, 32 years old, gravida IV, nulliparous, was referred for specialist care due to a high-risk spontaneous pregnancy after 
self-referring for antenatal care at 4 weeks of pregnancy. She reported no history of allergic reactions, recreational drug use, blood transfusions, surgeries, and was generally health. She had been diagnosed with chronic pyelonephritis as a child but was in remission since the age of 12 . Her menstrual cycle was regular, lasting 28 days, with moderately painful periods lasting five days. She was in a stable relationship with a 38-year old, healthy partner.

Her first and second pregnancy occurred spontaneously in 2008 and 2010 and ended at 14 and 15-16 weeks, respectively, with miscarriages and uncomplicated dilation and curettage. During the second pregnancy, she received luteal phase and early pregnancy support with dydrogesterone and also underwent genetic testing of fetal tissue, which did not reveal chromosomal abnormalities.

Her third pregnancy occurred spontaneously in 2012 and ended with preterm delivery and intrapartum demise of a male fetus (weight: $540 \mathrm{~g}$ ) at 23 weeks; post-partum manual exploration of the uterus was performed due to a suspected placental defect. The fetus did not bear signs of congenital pathology, which was confirmed at post-mortem. Placental histology demonstrated pathological immaturity of chorionic villae. During her third pregnancy, the patient received vaginal micronised progesterone from the first trimester; an obstetric pessary was inserted at 18 weeks.

Ms B tested negative for congenital thrombophilias, and she and her partner did not carry any genetic pathology.

During her fourth pregnancy, she was receiving vaginal micronised progesterone for 4 weeks of gestation (400 mg BID until 20 weeks, followed by 200mg OD), folic acid (until 13 weeks) and potassium iodide (throughout pregnancy). She had low risk of fetal chromosomal pathology, pre-eclampsia, and placental insufficiency according to first trimester screening. Due to her past obstetric history, she received preventative circular cervical cerclage using a mersilene tape at 15-16 weeks of pregnancy. At the time of the procedure, her cervical and vaginal swabs were normal, cervical canal was not widened, and cervical length measured by ultrasound reached $35 \mathrm{~mm}$.

At a 25-week scan, her cervix shortened to $20 \mathrm{~mm}$, and internal os widened to $15 \mathrm{~mm}$. To achieve additional mechanical unloading, we inserted a perforated silicone obstetric pessary (Arabin's pessary), and also carried out fetal respiratory distress syndrome (RDS) prevention. Considering the possible reduction in absorption of vaginal micronised progesterone due to the pessary, we changed the route of progesterone administration to oral (200 mg/day). The subsequent course of pregnancy was uneventful, and the patient did not require admission or additional tocolytic therapy.

The pessary and cerclage were removed at 37 weeks. At 38 weeks, she was admitted to a perinatal center with preterm rupture of fetal membranes. Her waters were clear, and she developed regular contractions two hours later and gave birth to a healthy boy (weight: $3200 \mathrm{~g}$, length: 50cm; Apgar score 8-9) after having been in labor for 9 hours 10 minutes (first phase: 7 hours; second phase: 2 hours; third phase: 10 minutes). Both were discharged on Day 4, in accordance with local standards for uncomplicated vaginal birth.

This case study demonstrates successful combined use of cerclage, obstetric pessary and micronized progesterone for the prevention of preterm birth in a patient with a history of preterm birth and cervical incompetence. However, wider introduction of this approach requires thorough testing in dedicated largescale studies. In addition, it would be beneficial to evaluate the pharmacodynamics of vaginal micronised progesterone in patients with obstetric pessaries.

\section{Acknowledgement}

None.

\section{Conflict of Interest}

No conflict of interest.

\section{References}

1. (2017) Reporting form No. 32 "Antenatal and postnatal medical care in 2012". Russian statistical year-book.

2. World Health Organization (WHO) (2017) Preterm birth factsheet.

3. Goldenberg RL, Culhane JF, Iams JD, Romero R (2008) Epidemiology and causes of preterm birth. Lancet 371(9606): 75-84.

4. Conde-Agudelo A, Romero R (2015) Predictive accuracy of changes in transvaginal sonographic cervical length over time for preterm birth: a systematic review and metaanalysis. Am J Obstet Gynecol 213(6): 789801.

5. Romero R, Conde-Agudelo A, El-Refaie W, Rode L, Brizot ML, et al. (2017) Vaginal progesterone decreases preterm birth and neonatal morbidity and mortality in women with a twin gestation and a short cervix: an updated meta-analysis of individual patient data. Ultrasound Obstet Gynecol 49(3): 303-314.

6. Lee SE, Romero R, Park CW, Jun JK, Yoon BH (2008) The frequency and significance of intraamniotic inflammation in patients with cervical insufficiency. Am J Obstet Gynecol 198(6): 633.

7. Ananth CV1, Getahun D, Peltier MR, Salihu HM, Vintzileos AM (2006) Recurrence of spontaneous versus medically indicated preterm birth. Am J Obstet Gynecol 195(3): 643-650.

8. Romero R, Nicolaides KH, Conde-Agudelo A, O’Brien JM, Cetingoz E, et al. (2016) Vaginal progesterone decreases preterm birth $\leq 34$ weeks of gestation in women with a singleton pregnancy and a short cervix: an updated meta-analysis including data from the OPPTIMUM study. Ultrasound Obstet Gynecol 48(3): 308-317.

9. Alfirevic Z, Stampalija T, Medley N (2017) Cervical stitch (cerclage) for preventing preterm birth in singleton pregnancy. Cochrane Database Syst Rev 6: CD008991.

10. Liem SM, van Pampus MG, Mol BW, Bekedam DJ (2013) Cervical pessaries for the prevention of preterm birth: a systematic review. Obstet Gynecol Int 2013:576723. 